\title{
Distribution of Modules among the Central Regions of the Genomes of Several Actinophages of Faenia and Saccharopolyspora
}

\author{
By JÖRG SCHNEIDER*† AND HANS J. KUTZNER \\ Institut für Mikrobiologie, Technische Hochschule Darmstadt, Schnittspahnstrasse 9, \\ D-6100 Darmstadt, FRG
}

(Received 17 August 1988; revised 23 November 1988; accepted 6 March 1989)

\begin{abstract}
The central regions of the genomes of $\phi \mathrm{FR} 114, \phi \mathrm{FR} 113$ and $\mathrm{Mp} 1$, three temperate phages of the thermophilic actinomycete Faenia, are shown to differ mainly with respect to modules of about $3.5 \mathrm{~kb}$, designated J-module ( $\phi \mathrm{FR} 114)$ and $\mathrm{N}$-module $(\phi \mathrm{FR} 113, \mathrm{Mp} 1)$. The distribution of J and $\mathrm{N}$ was observed amongst 22 phages of Faenia and Saccharopolyspora; J-module homology was found on six phage genomes, whereas homology to the N-module was detected on ten phage genomes.
\end{abstract}

\section{INTRODUCTION}

The evolution of tailed bacteriophages (Reanney \& Ackermann, 1982; Ackermann \& Dubow, 1987 ) is thought to be a combination of (1) successive changes of single genes caused by point mutations (Studier, 1979) and (2) the exchange of functional sets of genes (called modules) between not necessarily closely related phages (Botstein, 1980). The latter process facilitates rapid evolution which may enable the phages to adjust to host changes and to overcome host defences. Point mutations may slowly alter the modules (e.g. for host recognition) which, provided they remain functional, can in effect be tested in combination with different existing phage modules (e.g. for tail morphology), perhaps resulting in advantageous new bacteriophage blueprints.

Limited homologies between different phages have often been described and sometimes discussed as possible modules (Brzezinski et al., 1986), but the evolution and distribution of such modules has only been investigated thoroughly with some coliphages (Campbell \& Botstein, 1983; Kamp, 1987) or Mu-like phages of Pseudomonas (for a review of the work by Krylov et al. see Dubow, 1987).

$\phi$ FR114 and $\phi$ FR113 belong to a group of temperate and lytic phages of several host species within the actinomycete genera Faenia and Saccharopolyspora (Kempf et al., 1987; for host taxonomy see Embley et al., 1988; Greiner-Mai et al., 1988). The two phages were previously described as examples of diverging evolution by point mutations (Schneider et al., 1987). In this paper we demonstrate that they also differ by one module within the central regions; the distribution of the particular modules among both homo- and heteroimmune phages is discussed, including phages of Saccharopolyspora erythraea recently described by others (Brzeziǹski et al., 1986; Grund \& Hutchinson 1987; Smorawiǹska et al., 1988). Part of this work was presented at the 5th DECHEMA Jahrestagung der Biotechnologen, May 1987, in Frankfurt (Schneider \& Kutzner, 1988).

\section{METHODS}

Bacteria and phages. For DNA preparation all phages (see Table 1 for origins) were propagated on Faenia sp. TD8, kindly provided by A. Kempf (Darmstadt), whereas for host-range experiments the strains listed in Table 1

$\uparrow$ Present address: Angewandte Genetik, Fachbereich Biologie/Chemie, Universität Osnabrück, Barbarastrasse 11, D-4500 Osnabrück, FRG. 
were used. Phage $\phi$ SE6 was grown on $S$. erythraea DSM 40517 as it does not infect Faenia. Bacteria and phages were grown with GPHF media as described before (Schneider et al., 1987), Faenia and S. hirsuta at $37^{\circ} \mathrm{C}$ or $48^{\circ} \mathrm{C}$ and the mesophilic $S$. erythraea at $37^{\circ} \mathrm{C}$. Double-layer plates were inoculated from overnight cultures in GPHFbroth (supplemented with $5 \%, \mathrm{w} / \mathrm{v}, \mathrm{NaCl}$ for Faenia and $\mathrm{S}$. hirsuta for better formation of submerged spores) rather than with spores.

DNA manipulations and analysis of phage genomes. The procedures were as described by Schneider et al. (1987). For relatively accurate mapping of homologies within the central regions of the phage genomes by DNA hybridization, the relevant DNA fragments were cloned in pUC18 (Yanisch-Perron et al., 1985): the recombinant plasmids pJS54 and pJS55 ( $\phi$ FR114) and pJS50 ( $\phi$ FR113) have been described before (Schneider et al., 1987); pJS66 is a subclone of pJS55. pJS82 contains a HindIII-BamHI fragment covering the central region of Mp1.

DNA-DNA hybridization. Southern blotting was essentially as described by Wahl et al. (1979) except that biotinylated probes were used (Schneider \& Müller, 1988). Filters from the blotting procedure were baked for $60 \mathrm{~min}$ at $80^{\circ} \mathrm{C}$ and prehybridized at $55^{\circ} \mathrm{C}$ in SSCM $(6 \times \mathrm{SSC}$ with $0.7 \%$ dry skimmed milk; $1 \times \mathrm{SSC}$ is $0.15 \mathrm{M}-$ $\mathrm{NaCl}, 0.015 \mathrm{M}$-trisodium citrate, $\mathrm{pH} \mathrm{7.0)}$ and the biotinylated DNA-probe was added to a final concentration of $100-300 \mathrm{ng} \mathrm{m}^{-1}$. Usually $100 \mathrm{ng}$ biotinylated $\lambda \mathrm{DNA} \mathrm{ml}^{-1}$ was added to visualize $\lambda$ size standards; this probe did not hybridize with the DNA of the Faenia or Saccharopolyspora phages. The nick-translation was done as described by Hopwood et al. (1985) using Biotin-11-dUTP (Gibco BRL). Afterwards the hybridization mixture was stored at $-20^{\circ} \mathrm{C}$ for repeated use. The filter was briefly washed with $2 \times \mathrm{SSC}+1 \% \mathrm{SDS}$ followed by further washes $(2 \times 30 \mathrm{~min})$ which determined the stringency of the hybridization. The $\mathrm{G}+\mathrm{C}$ content of the phages was assumed to be $59 \mathrm{~mol} \%$, which is the value determined for $\phi$ FR114 by HPLC (E. Grund \& J. Schneider, unpublished data). High stringency was achieved with $0.15 \times \mathrm{SSC}+0.1 \% \mathrm{SDS}$ at $70^{\circ} \mathrm{C}$ whereas for medium stringency $0.2 \times \mathrm{SSC}+0.1 \% \mathrm{SDS}$ at $60^{\circ} \mathrm{C}$ was used. Finally the filter was blocked with SSCM $\left(20 \mathrm{~min}, 48^{\circ} \mathrm{C}\right)$ and the biotinylated DNA was detected using the BLUGENE detection system (Gibco BRL).

\section{RESULTS AND DISCUSSION}

\section{The $J$ - and $N$-modules}

$\phi$ FR 114 and $\phi$ FR 113 are closely related temperate phages as shown by similar restriction maps, although the central regions of their linear genomes exhibit considerable differences (Schneider et al., 1987). DNA hybridization revealed that the central region can be further subdivided (Fig. 1).

(1) The left part of the central regions differed with respect to restriction pattern but still showed considerable DNA homology under high-stringency conditions, a good example for diverging evolution by point mutations, which may affect some parts of a genome more than others (Campbell et al., 1986). Two independent, non-overlapping deletions within this area of $\phi$ FR113 are regarded as the origin of $\phi$ FR371 and $\phi$ FR755R (Fig. 1; Schneider et al., 1987). Similar deletions, recently described for the $S$. erythraea phage SE-3 and resulting in phage SE-5, were flanked by short repeats (Smorawiǹska et al., 1988; R. Brzeziǹski, personal communication); homologous recombination between these repeats could be the cause of the deletions in SE-5.

(2) In contrast to the left part, the right half of the central regions showed no homology at all, suggesting that this area corresponded to two distinct modules acquired from different sources. These modules were called J-module ( $\phi$ FR 114) and N-module ( $\phi$ FR113) following comparison with virulent $\phi F R v$ phages (see below). pJS54 (Fig. 4) was used as a probe partially specific for the J-module to screen other phages for its presence. Surprisingly, signals were detected with two of the three virulent $\phi F R v$ phages, $\phi F R v-J$ and P113, but not with $\phi F R v-N$.

The virulent $\phi \mathrm{FRv}$ phages $\phi \mathrm{FRv}-\mathrm{J}, \phi \mathrm{FRv}-\mathrm{N}$ and P113 are closely related to each other as shown by restriction fragment pattern (no restriction maps of these phages are available) and DNA hybridization (Fig. 2): under high-stringency conditions $\phi$ FRv-J and P113 DNA hybridized very well with each other, although a somewhat lower homology was observed within some fragments. $\phi \mathrm{FRv}-\mathrm{N}$, however, shared extensive homology with the genomes of the other two phages, with only a minor part showing no homology. This was not due to a deletion, as $\phi F R v-J$ and P113 have a region of similar size not hybridizing with $\phi \mathrm{FRv}-\mathrm{N}$. This part of the genome was called the J-module ( $\phi \mathrm{FRv}-\mathrm{J}$ and P113) and the $\mathrm{N}$-module $(\phi \mathrm{FRv}-\mathrm{N})$.

When total $\phi$ FR 114 DNA was used as a probe, no homology was detected with $\phi F R v-N$, and 


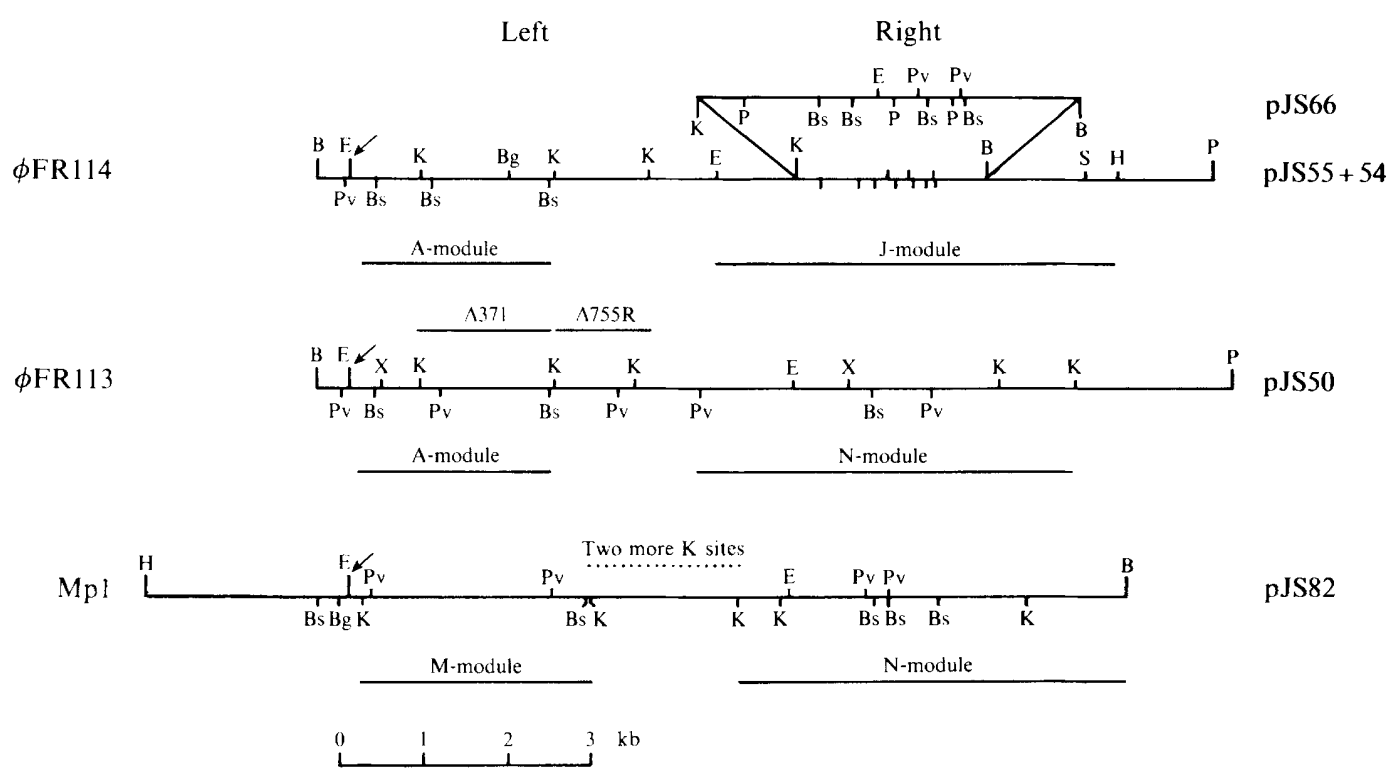

Fig. 1. The central regions of $\phi \mathrm{FR} 114, \phi \mathrm{FR} 113$ and Mpl. The position of the cloned fragments on the respective phage genomes is indicated in Fig. 4. The EcoRV sites marked by an arrow indicate the left border of the central region and are also shown in Fig. 4. The map of pJS54/55 is an improved version of the one recently compared to pJS50 (Schneider et al., 1987). Note that some of the restriction sites on pJS66 had not been recognized before. All three central regions were mapped with the same ten restriction endonucleases: B, BamHI ; Bg, BglII ; Bs, BstEII; E, EcoRV; H, HindIII ; K, KpnI : P, PstI ; $\mathrm{Pv}$, PvuII; S, SacII; X, XhoI. There is strong homology between the three central regions except in those areas indicated by labelled lines beneath the respective maps.

Right half. The lines indicate the region with no homology between $\phi$ FR114 and $\phi$ FR113 DNA and between $\phi$ FR114 and Mpl DNA. These areas correspond closely to the homologies found between $\phi$ FR1 14 and $\phi$ FRv-J DNA and between $\phi$ FR113 or Mp1 and $\phi$ FRv-N DNA and thus were called Jand $\mathrm{N}$-modules.

Left half. The lines indicate the non-homologous region between $\phi$ FR114 (or $\phi$ FR113; A-module) and Mpl (M-module) DNA. $\triangle 371$ and $\triangle 755 R$ mark the fragments of the $\phi$ FR113 genome which are deleted in $\phi$ FR371 and $\phi$ FR755R, respectively (Schneider et al., 1987).

the homology with $\phi \mathrm{FRV}$-J and P113 was limited to the J-modules of these phages. As expected, labelled $\phi \mathrm{FR} v-\mathrm{J}$ or P113 DNA did not hybridize with $\phi \mathrm{FR} 113$ but gave signals with the J-module of $\phi$ FR114. In spite of their strong homology, the J-modules from $\phi$ FR 114 and the two $\phi F R v$ phages had no comparable restriction pattern (data not shown). $\phi$ FR113 DNA as a labelled probe gave no signals with $\phi \mathrm{FRv}-\mathrm{J}$ and P113 but hybridized with the N-module of $\phi \mathrm{FRv}-\mathrm{N}$, and labelling of $\phi \mathrm{FRv}-\mathrm{N}$ DNA gave signals against $\phi \mathrm{FR} 113$ DNA only in the $\mathrm{N}$-module (data not shown).

Thus it appears that the temperate phage $\phi \mathrm{FR} 113$ and the apparently unrelated phage $\phi \mathrm{FRv}-\mathrm{N}$ share a highly homologous region of about $3.5 \mathrm{~kb}$, consequently termed the $\mathrm{N}$-module. Similarly, the temperate phage $\phi \mathrm{FR} 114$ and the virulent phages $\phi \mathrm{FRv}$-J and P113 (unrelated to $\phi F R 114$, but closely related to each other and $\phi F R v-N$ ) share a different module, the J-module. The chief differences between $\phi \mathrm{FR} 114$ and $\phi \mathrm{FR} 113$, which are otherwise very closely related, thus seems to be that the former carries the $\mathrm{N}$-module and the latter the J-module.

\section{Distribution of sequences homologous to the $J$ - and $N$-modules}

Whole genomes of $\phi \mathrm{FRv}-\mathrm{J}$ and $\phi \mathrm{FRv}-\mathrm{N}$ were used as biotinylated probes to screen all available phages known to infect Faenia and Saccharopolyspora for the occurrence of the J-and $\mathrm{N}$-modules. Both phages were used in parallel to ensure that the signals observed were due to one 
(a)

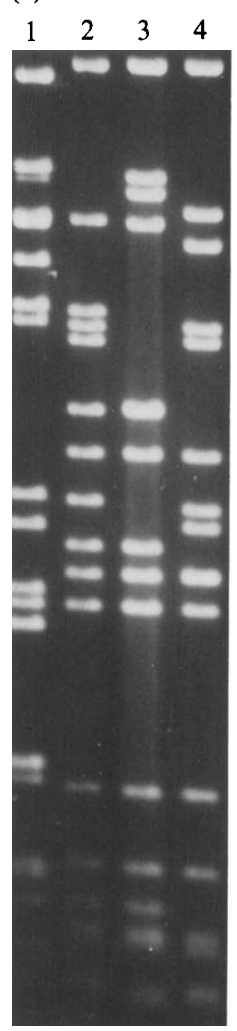

(b)

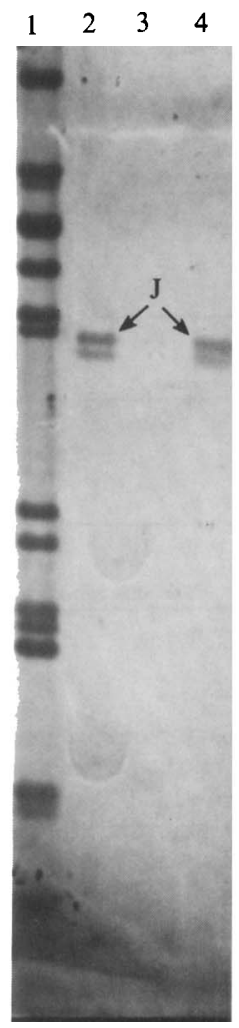

(c)

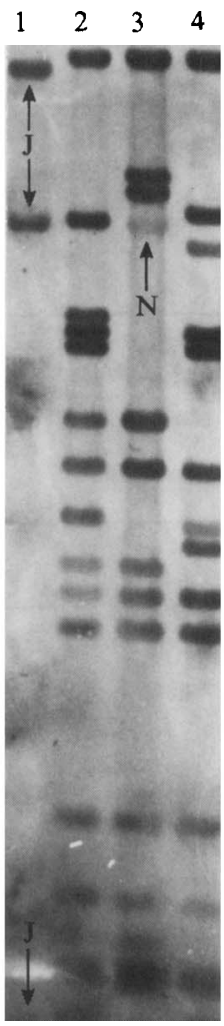

(d)

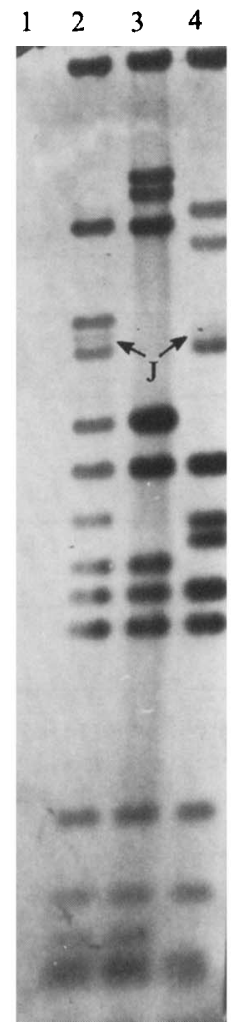

(e)

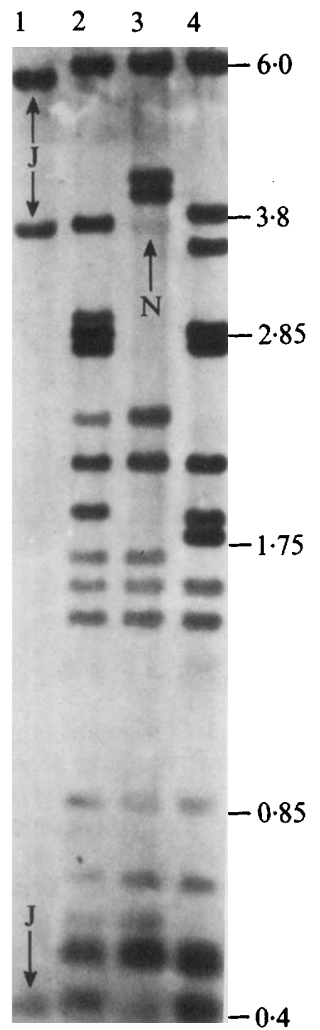

Fig. 2. Homologies between $\phi$ FR114, $\phi$ FRv-J, P113 and $\phi$ FRv-N. (a) Ethidium-bromide-stained agarose gel of BstEII digests of phage DNAs: (1) $\phi \mathrm{FR} 114$, (2) $\phi \mathrm{FRv}$-J, (3) $\phi \mathrm{FRv}-\mathrm{N}$, (4) P113. After transfer to nitrocellulose filters the restriction fragments were hybridized with biotinylated probes prepared from phage DNA of (b) $\phi \mathrm{FR} 114,(c) \phi \mathrm{FRv}-\mathrm{J},(d) \phi \mathrm{FRv}-\mathrm{N},(e) \mathrm{P} 113$. Approximate fragment sizes in $\mathrm{kb}$ are shown to the right. The hybridizations were carried out under high-stringency conditions. The fragments which represent the $\mathrm{J}$ - and $\mathrm{N}$-modules are indicated on each filter.

of these modules: if the same fragments of a phage were stained with both probes, this was assumed to be caused by genome fragments other than the $\mathrm{J}$ - or $\mathrm{N}$-modules. This screening demonstrated a considerable distribution of these modules among the phages tested (Table 1 , Fig. 3).

Homology to the J-module was found on the genomes of $\phi \mathrm{FR} 747$ and $\phi \mathrm{FRG} 9$, which are regarded as closely related to $\phi \mathrm{FR} 114$ (Schneider et al., 1987) and on $\phi \mathrm{FRa}-\mathrm{C}$, a temperate phage homoimmune with and related to the $\phi \mathrm{FR}$ phages.

Homology to the N-module was found on the genomes of several phages from different phage groups (Table 1), as detailed below.

(1) The $\phi \mathrm{FR}$ b phages are temperate Faenia phages which are only distantly related to the $\phi \mathrm{FR}$ phages and unrelated to the $\phi \mathrm{FRv}$ phages (J. Schneider, unpublished data).

(2) Phage 121 is an S. erythraea phage which cannot be propagated on host strains with a $\phi F R$ or $\phi \mathrm{FRb}$ prophage. It was originally isolated from a lysogenic strain of $S$. erythraea (Retinskaya $\&$ Rautenstein, 1960) but later could not be found to lysogenize available hosts (Brzeziǹski et al., 1986). It might thus be assumed to be a lytic mutant of an unknown temperate phage or to lysogenize only unknown host strains, as was demonstrated for phage Mpl (see below). Phage 121 is closely related to SE-5, which exhibited no homology to the J- or the N-module. Both 


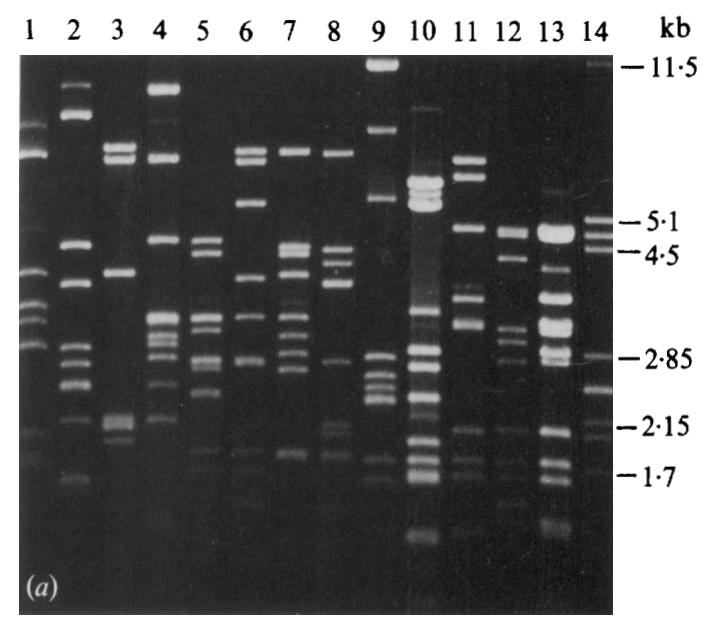

Fig. 3. Distribution of the J- and N-module amongst phages infecting Faenia and Saccharopolyspora. (a) Ethidium-bromidestained agarose gel of $B s t$ EII digests of phage DNAs. After transfer to nitrocellulose filters the restriction fragments were hybridized with biotinylated probes prepared from $(b)$ $\phi \mathrm{FR}_{\mathrm{v}-\mathrm{J}}$ and $(c) \phi \mathrm{FR} v-\mathrm{N}$ DNA (performed under medium-stringency conditions). The detections were stopped after $10 \mathrm{~min}(c)$ and $20 \mathrm{~min}(b)$, which explains the different staining intensities on the two filters. Fragments which were extensively stained by only one of the two probes are assumed to correspond to the $\mathrm{J}$ - or $\mathrm{N}$-modules and are indicated by arrows. Lanes: (1) P517, (2) 121, (3) $\phi$ SE6, (4) $\phi$ SE60, (5) $\phi$ FRb-P, (6) $\phi$ FRb$\mathrm{M},(7) \phi \mathrm{FRb}-\mathrm{D},(8) \phi \mathrm{FR} b-\mathrm{B},(9) \phi \mathrm{FRa}-\mathrm{E},(10)$ $\phi \mathrm{FRa}-\mathrm{C}$, (11) $\phi \mathrm{FRa}-\mathrm{A}$, (12) $\phi \mathrm{FRG9,} \mathrm{(13)}$ $\phi$ FR747, (14) $\lambda$ PstI standard.
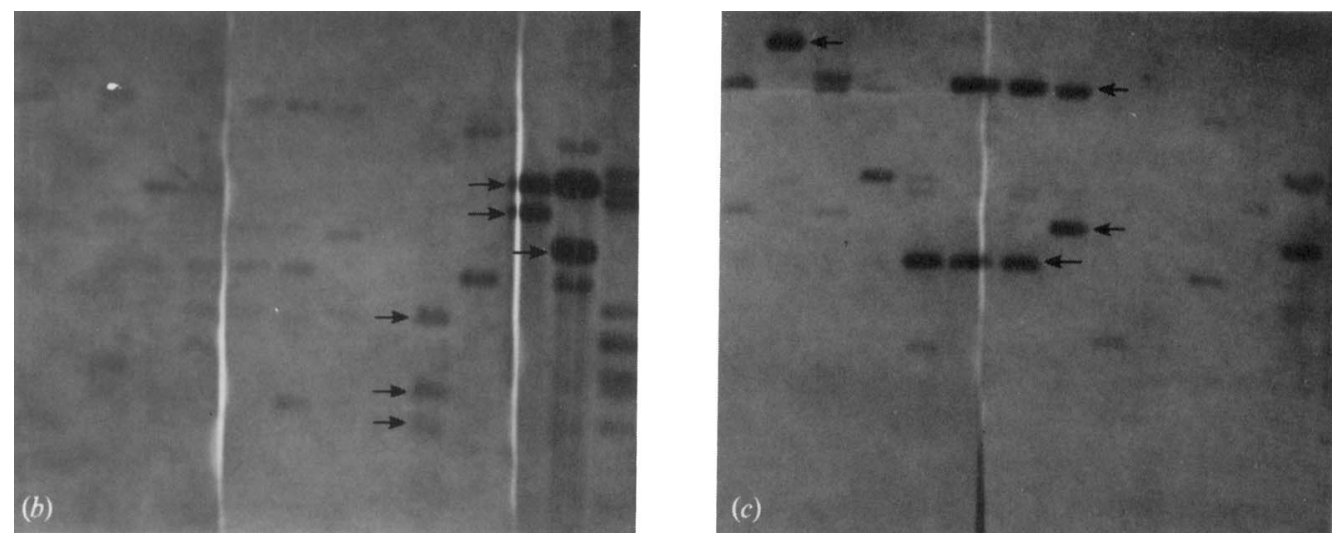

phages are distantly related to the $\phi F R$ phages but not to the $\phi \mathrm{FRv}$ phages (J. Schneider, unpublished data).

(3) Mpl was the first phage described for F. rectivirgula (Prauser \& Momirova, 1970) and since then has been a valuable tool in actinomycete taxonomy (e.g. Prauser, 1984). Although it has been considered to be a virulent phage it is not able to lyse strains lysogenic for $\phi F R 114$ and related phages. The isolation of a new species of Faenia (Faenia sp.; A. Kempf, personal communication) revealed that $\mathrm{Mpl}$ is a temperate phage as well: it easily lysogenized all four strains (e.g. TD8) of Faenia sp. and as a prophage it mediated immunity against $\phi$ FR114 (Table 1). The restriction map of Mpl could be aligned with the maps of $\phi$ FR 114 and $\phi$ FR113 (Fig. 4), although considerably fewer restriction sites were observed with the enzymes used for mapping. DNA hybridization demonstrated a high degree of homology between the three phages with the exception of the central region (Fig. 1): on the right part of the central region the $\mathrm{N}$-module was located, resulting in strong homology with $\phi$ FR113 DNA and no homology with $\phi$ FR114 DNA. The left half was different with respect to restriction pattern and revealed an area showing no homology with either $\phi \mathrm{FR} 114$ or $\phi \mathrm{FR} 113 \mathrm{DNA}$. These regions were termed A-module ( $\phi$ FR114 and $\phi$ FR113) and M-module (Mpl).

\section{Conclusion}

The idea of modular evolution requires a colinear organization of functional modules within different phages which are able to exchange such modules (Botstein, 1980). This may imply that 
Table 1. Characterization of the different Faenia phages

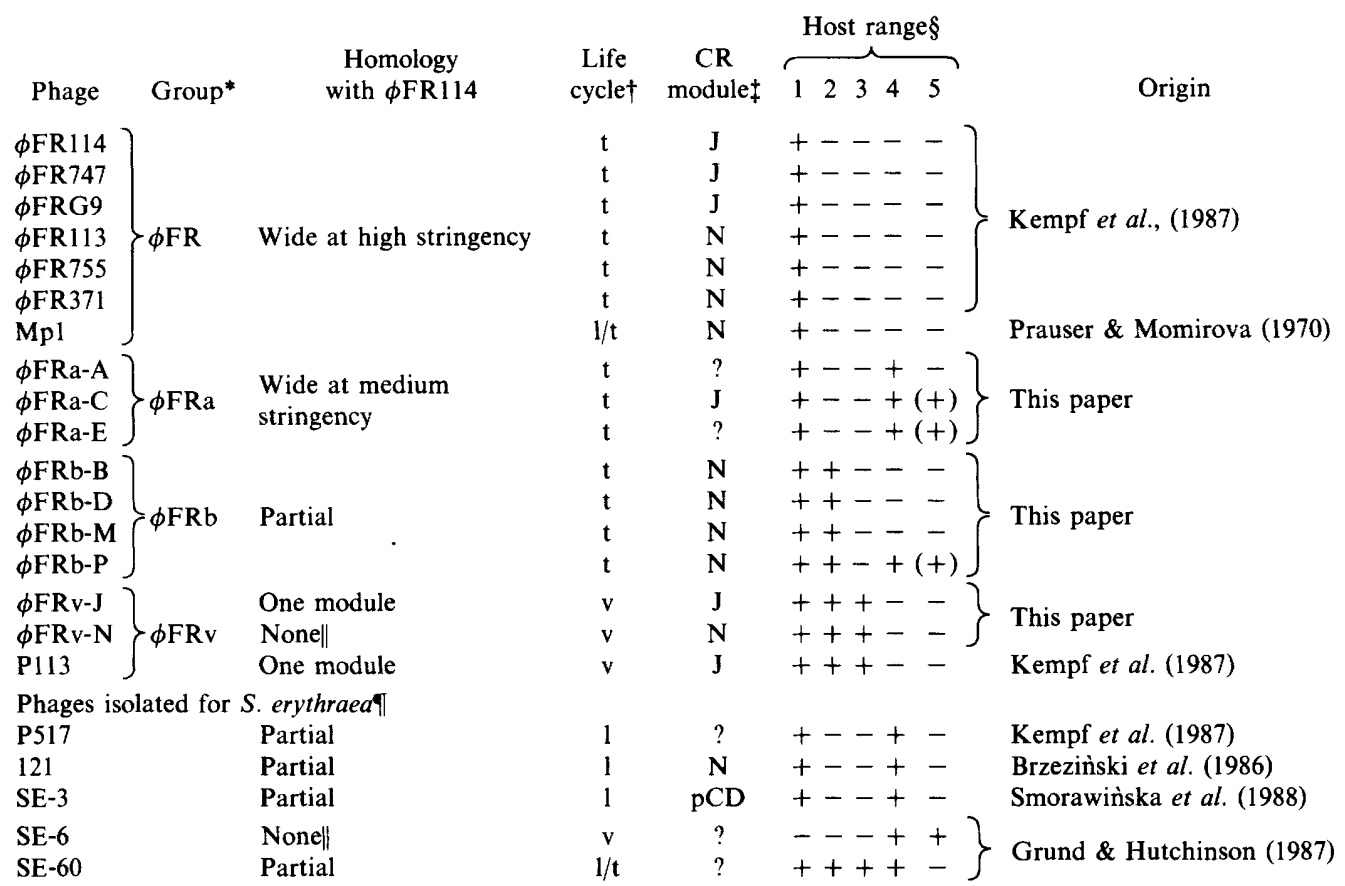

* Phages within one group exhibit a wide overall homology with each other.

$\dagger \mathrm{v}$, virulent; $t$, temperate; $1 / t$, host-dependent; 1 , lytic (i.e. no lysogenization observed but phage repressed by other prophages).

$\ddagger$ ?, central region (CR) module other than the $\mathrm{J}$ - $\mathrm{N}$-module and no homology with pCD3.

$\S 1, F$. rectivirgula DSM 43747 or Faenia sp. TD8; 2, F. rectivirgula DSM 43114 or Faenia sp. TD8 ${ }^{114}$ (lysogens of $\phi$ FR114); 3, Faenia sp. TD8 ${ }^{\mathrm{Mp} 1}$ (lysogen of Mp1); 4, S. erythraea DSM 40517; 5, S. hirsuta DSM 43463 (more positives were seen with other strains of $S$. hirsuta); $(+)$, after overcoming host restriction barriers.

$\|$ Partial homologies at low stringency.

II In contrast to the Faenia phages, the $S$. erythraea phages cannot be propagated at temperatures above $43^{\circ} \mathrm{C}$.

the $\mathrm{J}$ - and $\mathrm{N}$-modules, found on corresponding positions of otherwise closely related genomes such as $\phi \mathrm{FR} 114$ and $\phi \mathrm{FR} 113$, or $\phi \mathrm{FRv}-\mathrm{J}$ and $\phi \mathrm{FRv}-\mathrm{N}$, represent alternative genetic information responsible for similar functions. Furthermore, the same functions appear to be present in different types of phages such as the temperate $\phi F R$ and $\phi F R b$ phages, the lytic phage 121 , and the virulent $\phi \mathrm{FRv}$ phages. There is no indication to date of what these functions might be.

DNA homology studies and comparison of restriction maps suggest that at least two more modules analogous to the J-and N-module may exist. (1) Several phage DNAs show extensive (e.g. $\phi$ FRa-E) or partial (e.g. P517) homologies with $\phi$ FR114 DNA but do not contain the J- or $\mathrm{N}$-module. Homology studies suggest similar genome organization for these phages and at least one more $\mathrm{J} / \mathrm{N}$ type module (data not shown). The lack of restriction maps and the complex homology patterns do not allow a more precise description. (2) pCD3 (kindly provided by $R$. Brzeziǹski, unpublished data) is a probe specific for the central region of SE-5 (Brzezinsski et al., 1986). Preliminary data (not shown) indicate that the area from which pCD3 originated corresponds to the N-module of phage 121. pCD3 DNA failed to hybridize with DNA from any of the phages listed in Table 1. The accumulation of sites for particular restriction enzymes which otherwise are not found on SE-5 or 121 may suggest that this module originated from a different evolutionary line of actinophages ( $R$. Brzezinski, personal communication). 


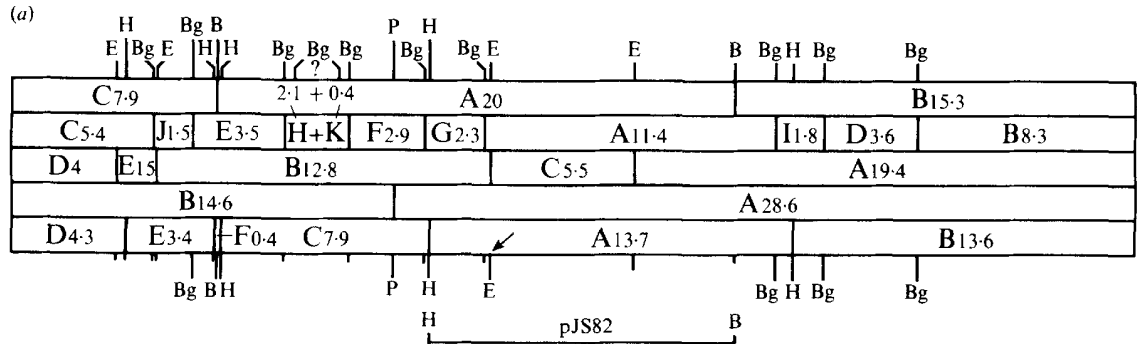

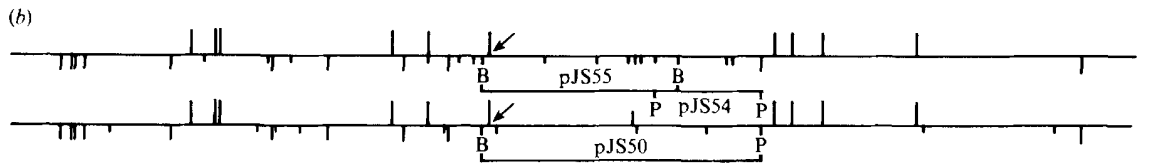

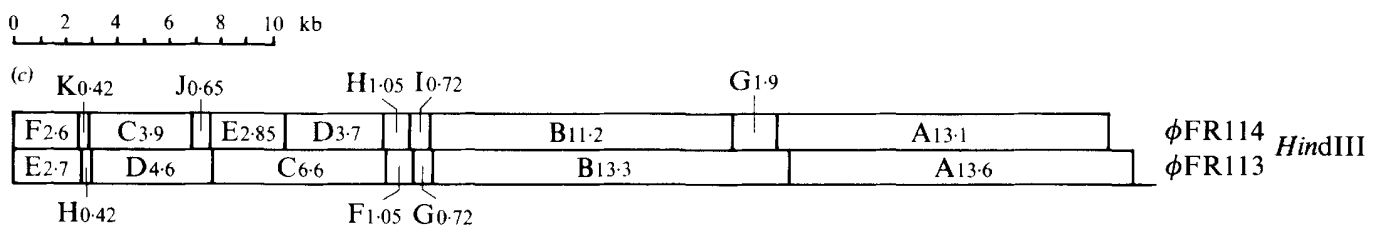

Fig. 4. The restriction map of Mp1 compared with the maps of $\phi$ FR114 and $\phi$ FR113. (a) Restriction map of Mpl (for abbreviation of restriction sites see Fig. 1). (b) Comparison of the restriction maps of $\mathrm{Mpl}, \phi \mathrm{FR} 114$ and $\phi \mathrm{FR} 113$ with seven enzymes. Sites which are common to all three phages are named on the map of $\mathrm{Mpl}$ and are indicated by long bars on the other two maps. Medium-length bars represent sites which are common to only two phages, and the restriction sites which are specific for each genome are shown by the short bars. The cloned fragments discussed in Fig. 1 are marked by the numbers of the recombinant plasmids. The arrows indicate the left borders of the central regions and are also shown in Fig. 1. For better alignment, the restriction map of $\phi F R 114$ was drawn as if $\phi F R 114(42 \mathrm{~kb})$ had the same genome length as $\phi \mathrm{FR} 113(43 \mathrm{~kb})$; the three small deletions which are responsible for the actual differences (Schneider et al., 1987) were thus ignored. (c) Comparison of HindIII restriction maps of $\phi$ FR114 and $\phi$ FR1 13 which had not been mapped previously. The diagram is to the same scale as the restriction maps recently shown (Schneider et al., 1987).

The identification and characterization of modules which are distributed among actinophages of Faenia and Saccharopolyspora is not only important for the investigation of bacteriophage evolution, but might also be interesting for vector development for this important group of industrial micro-organisms. Transfection experiments by Katz et al. (1988) with Saccharopolyspora erythraea and Streptomyces, and ourselves (Schneider et al., 1988) with $F$. rectivirgula, Streptomyces and Saccharomonospora, have demonstrated that these phages can be expressed in other actinomycetes and, conversely, that Saccharopolyspora erythraea or $F$. rectivirgula can express phages from other actinomycete genera, once the phage genome has passed the cell envelope. The combination of, for example, the $\phi \mathrm{C} 31$-derived phage vectors (Chater et al., 1985) with a host recognition module and perhaps an att-module from a Faenia phage could render this versatile set of vectors suitable for a number of species belonging to the Faenia/Saccharopolyspora cluster.

We thank Dr H. Prauser (Zentralinstitut für Mikrobiologie und Experimentelle Therapie, Jena, GDR) for Mpl and Dr C. R. Hutchinson (University of Wisconsin, USA) for $\phi$ SE6 and $\phi$ SE60. We are very grateful to Dr R. Brzezinski (University of Sherbrooke, Canada) for 121, SE-3 (first isolated by Drs Ostrowska-Krysiak and Blonska, Warsaw), pCD3, and several bacterial strains as well as for his cooperativeness and the permission to use his unpublished data. We also thank Dr K. F. Chater (John Innes Institute, Norwich, UK) for his advice and critical reading of the manuscript. Finally, we thank G. Kummer for her help with the manuscript and A. Lieke for excellent photographic assistance. This work was supported in part by the Fonds der Chemischen Industrie; J.S. received a PhD grant from the Technische Hochschule Darmstadt. 


\section{REFERENCES}

ACkermann, H.-W. \& Dubow, M. S. (1987). Viruses of Procaryotes. Boca Raton: CRC Press.

BotSTEIN, D. (1980). A theory of modular evolution for bacteriophages. Annals of the New York Academy of Sciences 354, 484-491.

Brzeziǹski, R., Surmacz, E., Kutner, M. \& PieKAROWICZ, A. (1986). Restriction mapping and close relationship of the DNA of Streptomyces erythraeus phages 121 and SE-5. Journal of General Microbiology 132, 2937-2943.

Campbell, A. \& Botstein, D. (1983). Evolution of lambdoid phages. In Lambda II, pp. 337-345. Edited by R. W. Hendrix, J. W. Roberts, F. W. Stahl \& R. A. Weisberg. Cold Spring Harbor, NY: Cold Spring Harbor Laboratory.

Campbell, A., Din Pow Ma, Benedik, M. \& LIMBERGER, R. (1986). Reproductive isolation in procaryotes and their accessory DNA elements. In Antibiotic Resistance Genes: Ecology, Transfer, and Expression (24th Banbury Report), pp. 365-380. Edited by S. B. Levy \& R. P. Novick. Cold Spring Harbor, NY: Cold Spring Harbor Laboratory.

Chater, K. F., King, A. A., Rodicio, M. R., Bruton, C. J., Fisher, S. H., Piret, J. M., Smith, C. P. \& Foster, S. G. (1985). Cloning and analysis of Streptomyces DNA in $\phi \mathrm{C} 31$-derived vectors. In Microbiology - 1985, pp. 421-425. Edited by J. D. Schlessinger. Washington, DC: American Society for Microbiology.

Dubow, M.S. (1987). Transposable Mu-like phages. In Phage Mu, pp. 201-214. Edited by N. Symonds, A. Toussaint, P. Van De Putte \& M. M. Howe. Cold Spring Harbor, NY: Cold Spring Harbor Laboratory.

Embley, T. M., Smida, J. \& Stackebrandt, E. (1988). Reverse transcriptase sequencing of $16 \mathrm{~S}$ ribosomal RNA from Faenia rectivirgula, Pseudonocardia thermophila and Saccharopolyspora hirsuta, three wall type IV actinomycetes which lack mycolic acids. Journal of General Microbiology 134, 961-966.

Greiner-MaI, E., KemPF, A., KorN-WendisCh, F. \& KUTZNER, H. J. (1988). Studies on the causative agents of farmer's lung: the actinomycete genera Faenia, Saccharomonospora and Thermoactinomyces. DECHEMA Biotechnology Conferences: Technology of Biological Processes - Safety in Biotechnology Applied Genetic Engineering, vol. 1, pp. 491-496.

GRUND, A. D. \& Hutchinson, C. R. (1987). Bacteriophages of Saccharopolyspora erythraea. Journal of Bacteriology 169, 3013-3022.

Hopwood, D. A., BibB, M. J., Chater, K. F., Kieser, T., Bruton, C. J., Kieser, H. M., Lydiate, D. J., SMith, C. P., WARD, J. M. \& SchrempF, H. (1985). Genetic Manipulation of Streptomyces - a Laboratory Manual. Norwich: John Innes Foundation.

KAMP, D. (1987). The evolution of Mu. In Phage $M u$, pp. 259-269. Edited by N. Symonds, A. Toussaint, P. Van De Putte \& M. M. Howe. Cold Spring Harbor, NY: Cold Spring Harbor Laboratory.

KatZ, L., Chiang, S.-J. D., Tuan, J. S. \& Zablen, L. B. (1988). Characterization of bacteriophage $\phi$ C 69 of Saccharopolyspora erythraea and demonstration of heterologous actinophage propagation by transfection of Streptomyces and Saccharopolyspora. Journal of General Microbiology 134, 1765-1771.

KempF, A., Greiner-Mal, E., Schneider, J., KornWENDISCH, F. \& KUTZNER, H. J. (1987). A group of actinophages of Faenia rectivirgula. Current Microbiology 15, 283-285.

Prauser, H. (1984). Phage host ranges in the classification and identification of Gram-positive branched and related bacteria. In Biological, Biochemical and Biomedical Aspects of Actinomycetes, pp. 145-159. Edited by L. Ortiz-Ortiz, L. F. Bojalil \& V. Yakoleff. London: Academic Press.

Prauser, H. \& Momirova, S. (1970). Phagensensitivität, Zellwandzusammensetzung und Taxonomie einiger thermophiler Actinomyceten. Zentralblatt für allgemeine Mikrobiologie 10, 219-222.

REANNEY, D. C. \& ACKermanN, H.-W. (1982). Comparative biology and evolution of bacteriophages. Advances in Virus Research 27, 205-280.

Retinskaya, V. I. \& Rautenstein, YA. I. (1960). The lysogenicity of Actinomyces erythraeus cultures and the isolation of their specific actinophages. Microbiology 29, 849-855.

SCHNEIDER, J. \& KUTZNER, H. J. (1988). A family of phages of the thermophilic actinomycete genus Faenia. DECHEMA Biotechnology Conferences: Technology of Biological Processes - Safety in Biotechnology - Applied Genetic Engineering, vol. 1, pp. 255260.

Schneider, J. \& Müller, L. (1988). DNA-DNA Hybridisierung mit biotinylierten DNA-Sonden. Forum Mikrobiologie 11, 254-262.

Schneider, J., Aguilera Garcia, I. \& Kutzner, H. J. (1987). Characterization of a family of temperate actinophages of Faenia rectivirgula. Journal of General Microbiology 133, 2263-2268.

Schneider, J., Gayer-Herkert, G., Greiner-Mai, E. \& KUTZNER, H. J. (1988). Transfection of Faenia rectivirgula with phage DNA from different actinomycete genera. Book of Abstracts of the 208th Meeting of the Genetical Society, 13th-15th April 1988, p. 41 Norwich: John Innes Institute.

SmorawiǹsKa, M., Denis, F., DeRY, C. V., Magny, P. \& BRZEZIǸsKI, R. (1988). Characterization of SE-3, a virulent bacteriophage of Saccharopolyspora erythraea. Journal of General Microbiology 134, 1773-1778.

STUDIER, F. W. (1979). Relationships among different strains of $\mathrm{T} 7$ and among T7-related bacteriophages. Virology 95, 10-76.

Wahl, G. M., Stern, M. \& Stark, G. M. (1979). Efficient transfer of large DNA fragments from agarose gels to diazobenzyloxymethyl-paper and rapid hybridization by using dextran sulfate. Proceedings of the National Academy of Sciences of the United States of America 76, 3683-3687.

YANISCh-PERRON, C., Vieira, J. \& Messing, J. (1985). Improved M13 phage cloning vectors and host strains: nucleotide sequence of the M13mp18 and pUC19 vectors. Gene 33, 103-109. 